\title{
Get Wet!
}

NEW from Seamless... all-in-one disposable skin scrub trays and packs, including antiseptic solution, and latex surgeon's gloves.

Complete: Towels, winged sponges, surgeon's gloves, sponge sticks...even an antiseptic paint and scrub

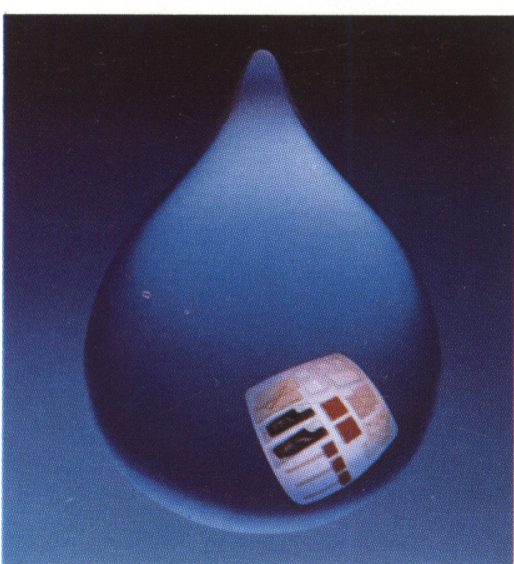

solution. A complete kit for a Sterile: No risk of crosscomplete skin scrub procedure. contamination. Cleaning and sterilization time-and the associated costs-are eliminated.

Convenient: Completely disposable, like all Seamless Skin Scrub Trays. Use it

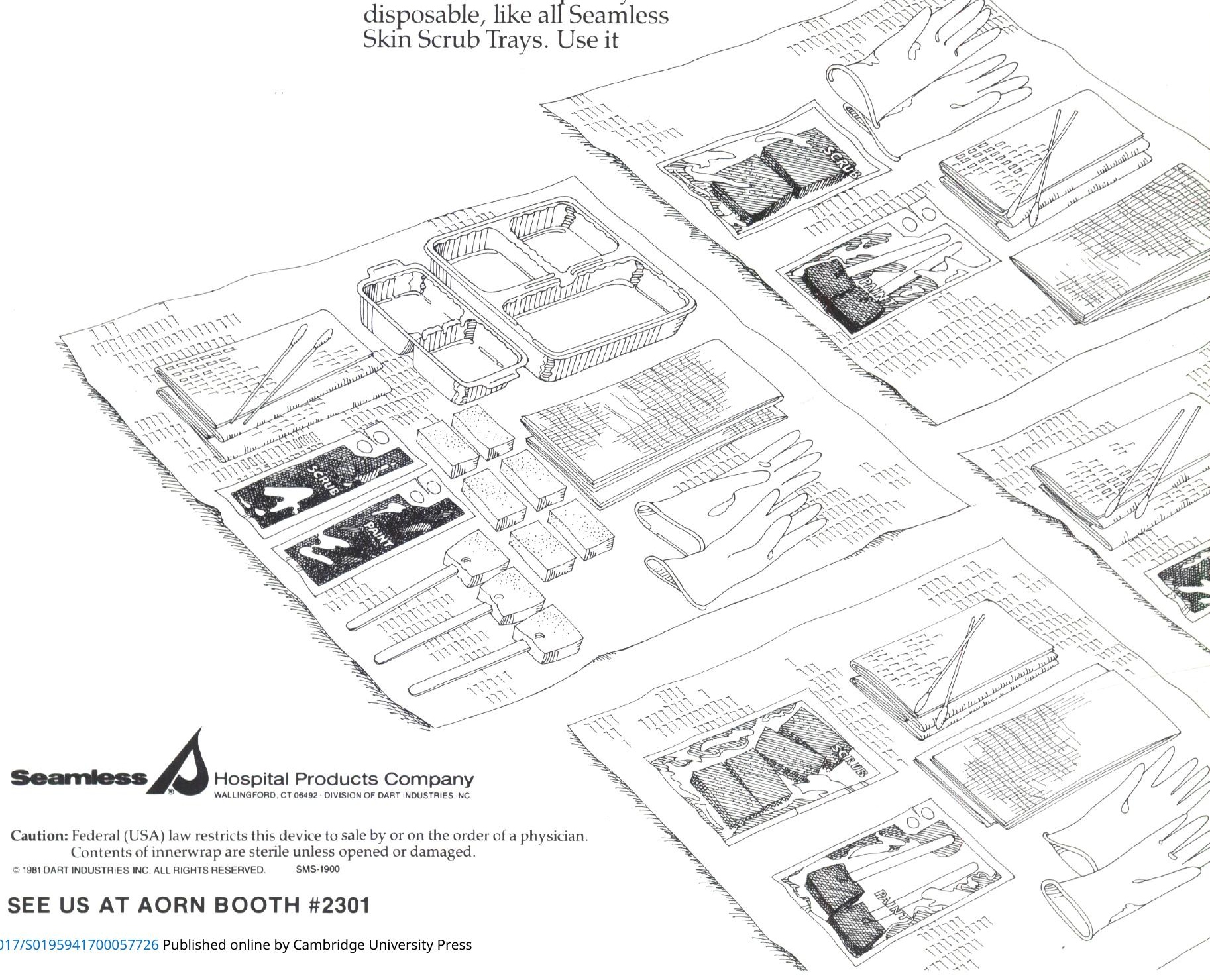

once...throw it away. Solution packets have special ring handles for easier opening, even with wet hands.

Four options: Four different component assortments available. Choose the tray or pack you need for practically any procedure.

Get more information about Seamless Skin Scrub Trays and Packs. Write: Seamless Hospital Products Company, Box 828, Barnes Industrial Park

North, Wallingford, CT 06492. Or call: 800-243-3030. 


\section{You can't beat

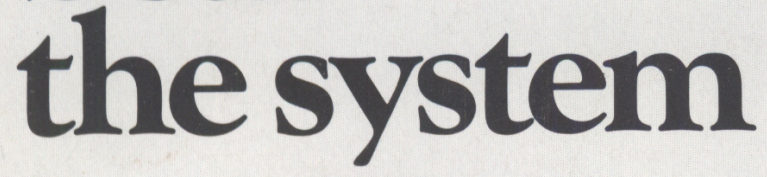

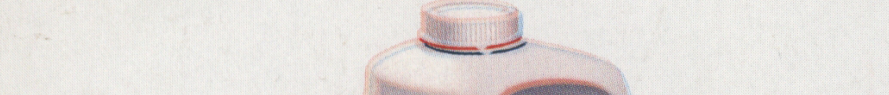

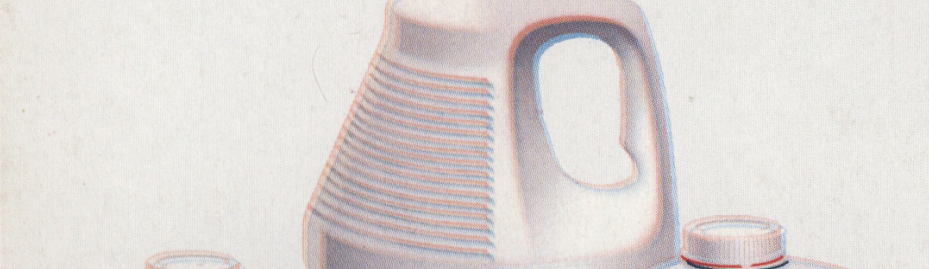

C6

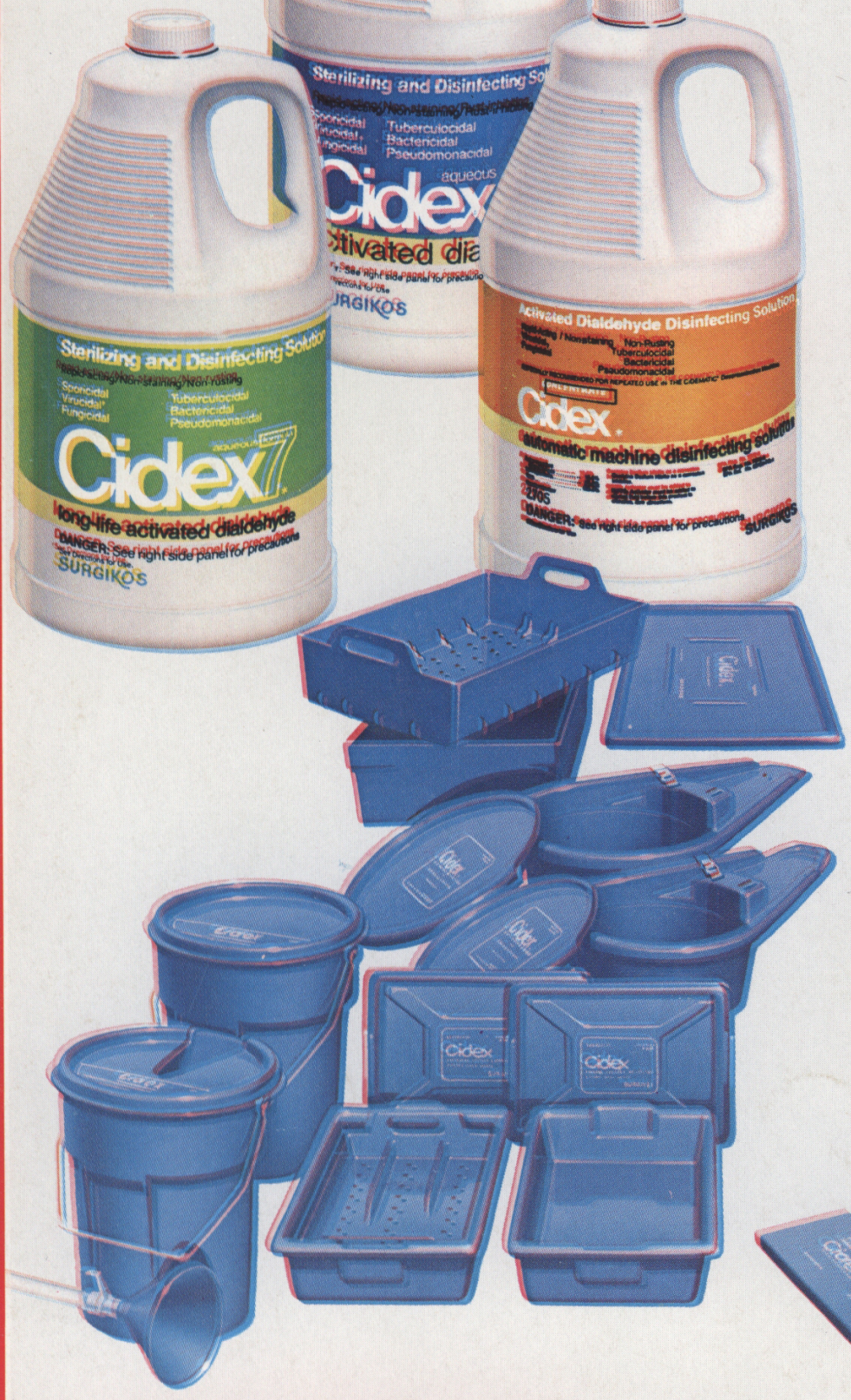

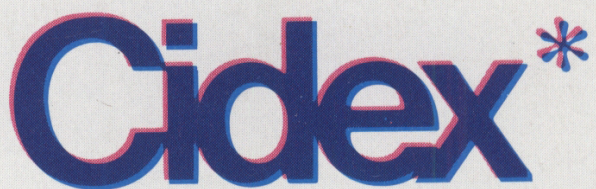
integrated sterilizing/
disinfecting system The Solutions

Years of research and clinical experience confirm the efficacy of CIDEX* Solutions and their safety on instruments of all kinds. No other solutions provide a comparable range of benefits.

Only CIDEX Solutions offer you a 14-day solution, a 28-day solution and a machine concentrate to best fit your needs.

\section{The Systems}

Save time, minimize handling and risk of equipment damage, maximize efficiency with the right CIDEX Sterilizing/Disinfecting Tray or Bucket System for your job.

\section{The Proof}

The two-minute

EFFECTIVENESS TEST

KITS add a special

dimension of safety

to your total patient

care system.
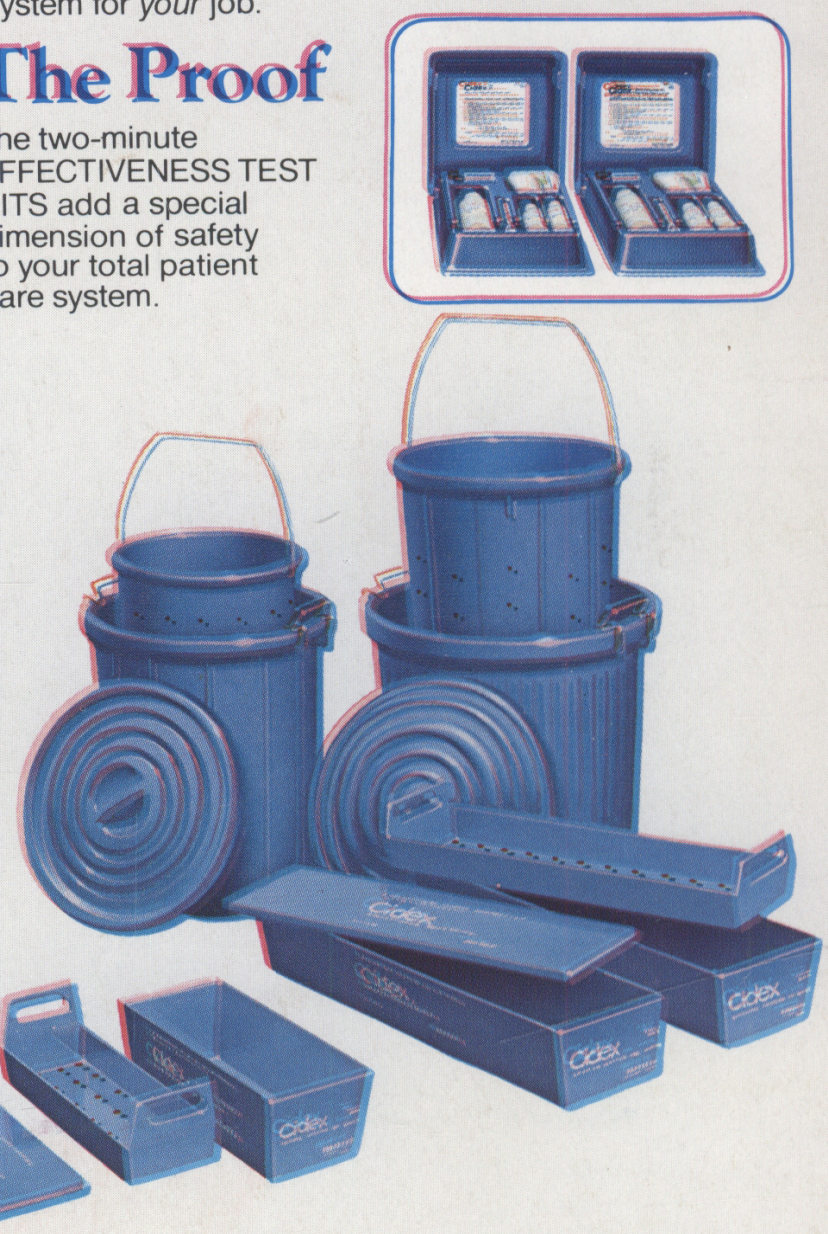